\title{
Volunteerism and international sport organisations: XVII. Mediterranean Games
}

\author{
Pinar GUZEL ${ }^{1}$, Hulya UNLU², Selhan OZBEY¹, Melike ESENTAS ${ }^{3}$ \\ ${ }^{1}$ School of Physical Education and Sport, Celal Bayar University, Manisa, Turkey. \\ ${ }^{2}$ Faculty of Sports Science, Gedik University, Istanbul, Turkey. \\ ${ }^{3}$ School of Physical Education and Sport, Batman University, Batman, Turkey \\ II. Recreation Studies Congress 31 October- 3 November 2013, Oral Presentation, Kuşadası, Aydın, Turkey. \\ Address Correspondence to M. Esentas, melike.esentas@windowslive.com
}

\begin{abstract}
After the recent candidacy process and while the Olympic Games are going on to be a dream, very important and large-scale organizations are continuing to be done in our Country. The head of them is XVII. Mediterranean Games which can not be placed in Greece because of economical reasons. One of the most important activities as such large and the successful execution of the multi-level voluntary organization of sporting events lead voluntary organization. The aim of this study; is to determinate the demographics and causes of participation of volunteers who are employed in the Games of which Mersin is the host, and to determinate the volunteers at the individual and activity level during the Games. In this study, the method of qualitative research approach is applied on 29 employed volunteers in Games. At the end of the interviews face to face with volunteers; the assessments on individual and activity level during the organisation and demographic characteristics and causes of participation are revealed.
\end{abstract}

Keywords: International sport activities, Mediterranean Games, voluntariness.

\section{INTRODUCTION}

Individuals prefer to be voluntary evaluate their free time, to be a part of the exchange, to make a difference, to have fun, to provide psychological contribution, to exit from routine, show their commitment, to help someone and to learn to be collaborative, togain new skills or improve existing skills, to recognize the new environment, to defend something they believe, to win a status and to provide cultural interaction. The volunteering is a state of that individual can use together or separately physical strength, time, knowledge, skills and experience in accordance with fully voluntarily, for the purpose of solidarity and cooperation, regardless of individual interests, without any financial expectation, just with a desire to be useful to society. (12). Social cohesion and trust, for example, thrive where volunteerism is prevalent. Volunteerism is not only the backbone of civil society organizations and social and political movements, but also of much health, education, housing and environmental programmes and a range of other civil society, public and private sector programmes worldwide. It is an integral part of every society (3).

According to Figure 1 volunteers; are the individuals who is a state to present her/his physical power, time, knowledge, one or more skills and the experience for usual non-governmental organizations or projects and who has financial gain expectation in exchange. While he/she is in cooperation, he/she is a model to himself and his/her environment. The interaction between stakeholders is provided by the activities.

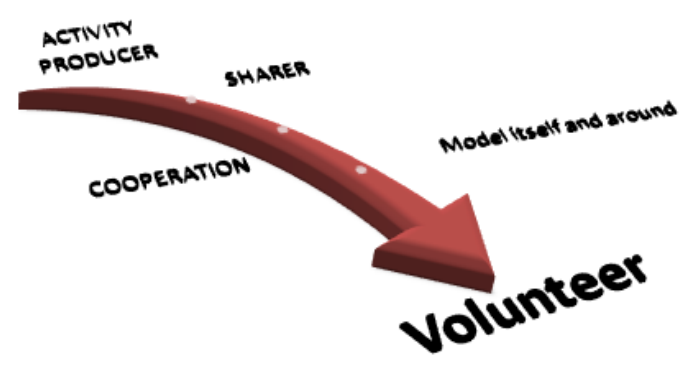

Figure 1. The main features of volunteers. 
The concept of volunteering in sport is experienced in different platforms and requirements. Voluntary contributions can be provided in very activity around developing all kinds of sporting events. Volunteers who take part in international sport organizations and Olimpic Games, are employed in as effective positions as professional staff (4). The successful completion of sports organizations is owed to volunteers. Great events are achieving success with the support of volunteers. Volunteers working in international sports organizations, perform their duties in a professional position as effectively as a professional staff (7). There is a direct correlation between the development levels of volunteering with the country. The importance of voluntary in national and international organizations has a great importance in terms of both finance and of realizing their information, skills, experience and talents (12).

According to figure 2 the volunteerism; helps to individuals developping their social attributes; make them gain new skills, and support their creativity. Make the public servants gain experiences which will add value to their career and get know themselfs. Helps to the awatness to be created in community as well as general interpublic development in long terms thank to volunteer studies of individuals in public, private sector and civil society.

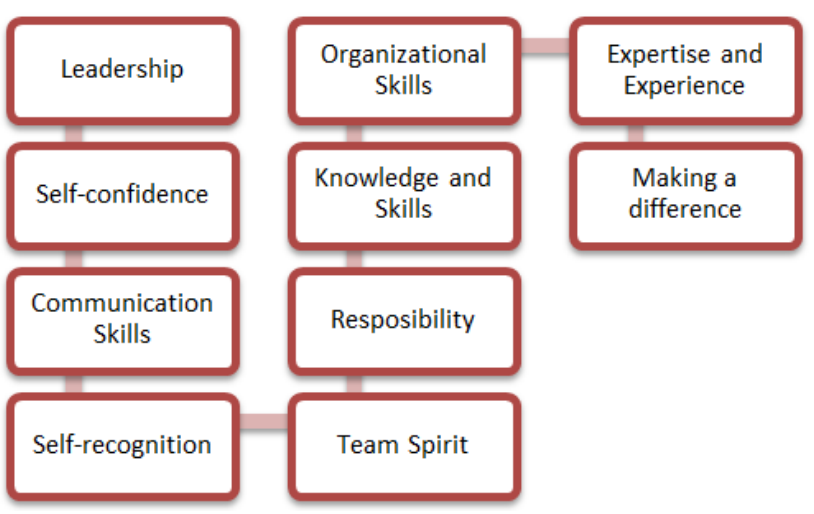

Figure 2. Benefits of volunteering.

The importance of volunteering in the organization is very large. The volunteer must continuation of the organization holding their motivation on high level because satisfaction of the audience and the contestants participating in the activity is directly proportional to meeting the needs and expectations of volunteers.

The importance of volunteers in sport events in last years has begun to appear a lot more. The volunteers have been an important part of sport services and sport management (2), because they support sport manager in areas of the sports quality, quantity in the sport organizations (10). Volunteers are working in local communities and sports programs. Worldwide or regional championships, they are taking their place national and international sports organizations. Employed volunteers have been effective on success of the organizations by being actif in accordance with the personal qualities within the organization. It is out of question that Volunteers take charge for their efforts and the effort. Volunteers try to demonstrate their qualifications by spending their time and energy in maintaining the organization troubleless. Thus, the organizing committees want to get the maximum rate from them by identifying in detail their motives, qualities, the needs and expectations (7).

As one of the world's leading organization of the World Mediterranean Games was put forward first in 1948 at the London Olympics. The Games arranged between countries which has coast to Mediterranean, are organized in order to provide social and cultural rapprochement. With similar structure and same rules as the Olympic Games, the Games go on during 15 days. Organized in both the city and the country which have coast to Mediterranean Sea, the Mediterranean Games was organized once in Izmir in 1971 and twice in Mersin in 2013 (6).

To achieve the objective of this research we will seek to answer the following questions:

1. What are the demographic characteristics and participation reasons of volunteers employed in the game?

2. What are the reviews regarding the personal development of the volunteers and events coverage during the Games?

\section{MATERIALS \& METHODS}

\section{Research Model}

Among one of the qualitative research techniques, the case study method were used. It is possible to define the qualitative research as a research in which qualitative data collection methods used such as observation, interviews and document analysis, in which a qualitative process is followed in aim of revealing realistically and bodily the perceptions and events in the natural environment (14). The reason of using qualitative research model in this reseach is; to reveal the perseptions covering the experiences, thinkings, expectations and suggestions of participants during 
the Mediterranean Games. Thus; firstly the litterature about the volunteer description has been observed in detail. Then, the definitions about being volunteering in great sport activities and general features of volunteernism have been identified. The interview model is face to face with participants employing as volunteer in XVII. Mediterranean Games was used and recorded.

\section{Participants}

During the Mediterranean Gamesorganized from 20 to 30 June 2013, they were formed from 29 persons who are employed as volunteer in different departments, plant and sport branchs. Volunteers are the participants who are employed in predicted units (Hotels, Transport, Accommodation, Attendance, Opening and Closing) and sport branchs (tennis, basketball, volleyball, soccer, badminton, swimming, water polo, taekwondo, karate, cycling and sailing). These participants have been chosen randomly with permission of the relevant departments responsible.

\section{Profiles of participants}

Personal information of participants is given in Table 1. Referring to Table 1 Demographic characteristics of the participants; age, sex, education, department of faculty, the department where he/she is employed, who had been volunteer at once and their sport branchs where they are employed.

\section{Research area}

The interviews made during the study were organized in areas that the participants preferred willingly, quiet and indistractive and suitable for interviewing. These areas were placed in plants where they had employed. Call time had been 15-20 minutes. Some volunteers who participated in the study have encountered in different plants, but the interview was held only once.

\section{Researcher's role}

One of the researchers in executive position and other three in volunteer position have employed as volunteer in 2005 Summer Universiade organized in İzmir. In addition, researchers have been continuing as the founder and supervision of volunteer clubs. They have been working as volunteer as a volunteer in various activities at the University and Manisa province.

\section{Data collection and Preparation of Interview Form}

As the data collection method in this research, "interview" approach, and in this approach "interview form method" had been used. Interview form prepared by experts in the field of research; is composed of two parts including questions relating to personal information and the subject of research.

\section{Interviews}

The face-to-face interviews made in this study; with 29 persons who are employed as volunteer in different departments, plant and sport branchs in result of preinterview and observation at XVII. Mediterranean Games on 20-30 June 2013.

The demographic characteristics of the participants to the survey are detailed in Table 1. The appointment received from the participants with whom face to face interviews were made and given short information about and the subject. The interviews were recorded with a tape recorder. For recording, the participants were asked to fill in for ethical consent. Call time had been 15-20 minutes.

\section{Analysis of the data}

In the study, analysis of the data in an understandable form, to achieve the cause-effect relationships examining the conclusions and interpretation of findings, the qualitative analysis "descriptive analysis" method was used. The purpose of this analysis, the raw form is introduced into a usable form of data that the readers can understood and if they want they can use.

The data obtained from all participants collected in computer and in a single text encoding. In this phase a group of three people worked. Themes uncovered independently from each other are converted into a common framework as a result of work done later. The volunteers interviewed in the study are coded as K1, K2, .... K29.

\section{Validity and Reliability}

The validity of the research study was carried out taking into account the following considerations.

$>$ It is always check whether findings were consistent and meaningful in themself.

$>$ The obtained data are consistent with the conceptual framework previously established.

Findings were both recorded on both audio recording device controlled via short notes. Thus, it is provided that findings have created a meaningful whole. 
Table 1. Participant profiles.

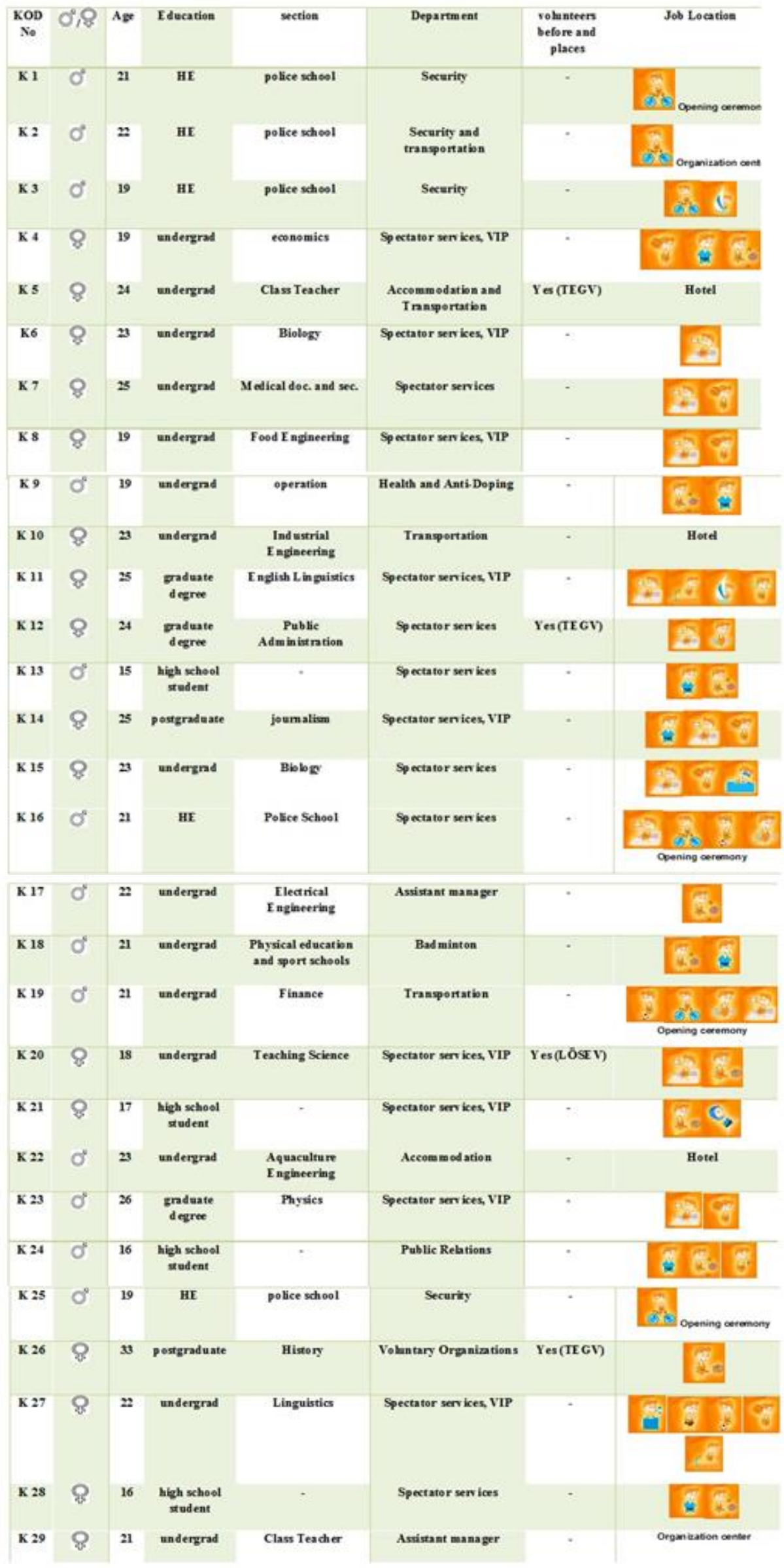

Turk ل Sport Exe 2015; 17(I): 84-91 
Reliability study in research was carried out taking into account the following considerations:

$>$ The methods and stages of research are described in a clear and detailed manner.

Research questions were expressed in a clear format.

Data were collected in detail and in a form suitable for object and stored so as to be examined by others.

> The results interrelated in a with the data clearly demonstrated.

At the end of the anaylsis obtained from volunteers (Table 1); the age average of 13 men, 16 women volunteer is 21.5 of whom \%72.4 are university student. Just one of the students from different faculties is from Faculty of Sport Sciences. Many of the volunteers (72.4\%) worked over multiple tasks in an event process. While \%14 of them has participated to volunteer activities in foundations such as LÖSEV (Foundation for Children with Luekemia) and TEGV (Educational Volunteers), all of the volunteers in this research stated that they volunteered for the first time in a sports event (Figure 3). Sertbaş (2006); in her study named 'participation reasons to organization volunteer human sources employed at 2005 Summer Universiade and anaylsis of motivational factors'; reached similar conclusions such as most of the participants involved in an activity previously served as outside sports activities. Auld (2004); in study named 'Behavioural characteristics of student volunteers', eached conclusions about that the majority of volunteers were students.

Have you previously worked as a volunteer in an organization?

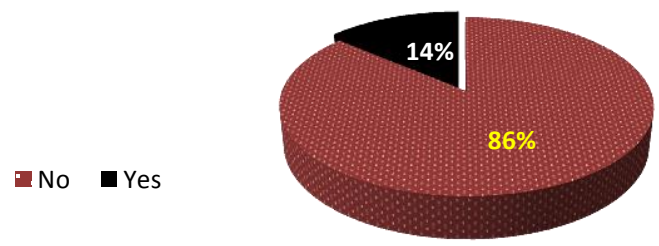

Figure 3. Previously working as a volunteer rate.

When analyzed the data if participants of what they want to be volunteer again to such an organization, we get \%100 yes (Figure 4).
Participation Reasons; before the organization, the reasons volunteers participated in activity; can listed as Personal development, gaining experience, gaining certificates and socialization and communication. Reasons and rates of the volunteers noted in Figure 5.

Do you apply for volunteering in another organization again ?

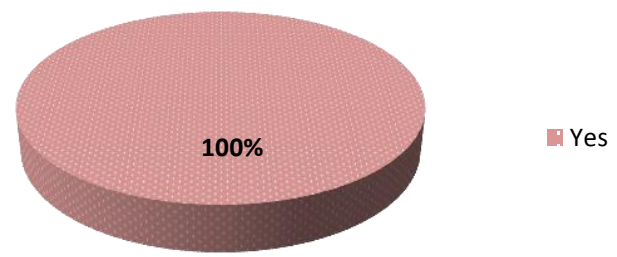

Figure 4. Requests of volunteers to be a volunteer again.

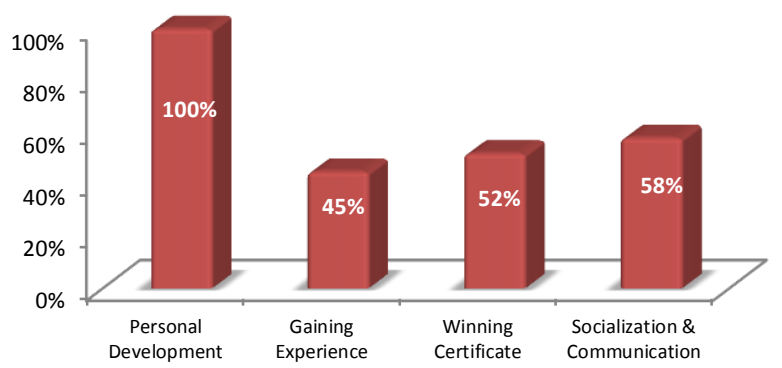

Figure 5. Reasons of volunteers participating to activities.

The opinion of volunteers about contributions of their Individual Development and general assessment of the Organization are noted as code on Figure 6.

Individual Development; All of the participants stated that the cause of willingness is to contribute is the personal development. Indicated as reasons for participation, personal development; gave the information that they gained any other achievements from gaining experience, gaining certificates and socialization and communication during the activity. These achievements are the recognition of crisis management and new sports. Based on these findings, participants thoughts;

"I I think that duties $i$ charged here will contribute to my future professional life" (P1, P2, P3, P6, P9...) "I am meeting with people from different cultures, and this provides me both to develop my foreign language and to communicate and to socialize" (P1, P2, P4, P5, P7, P8, P13, P16...) 


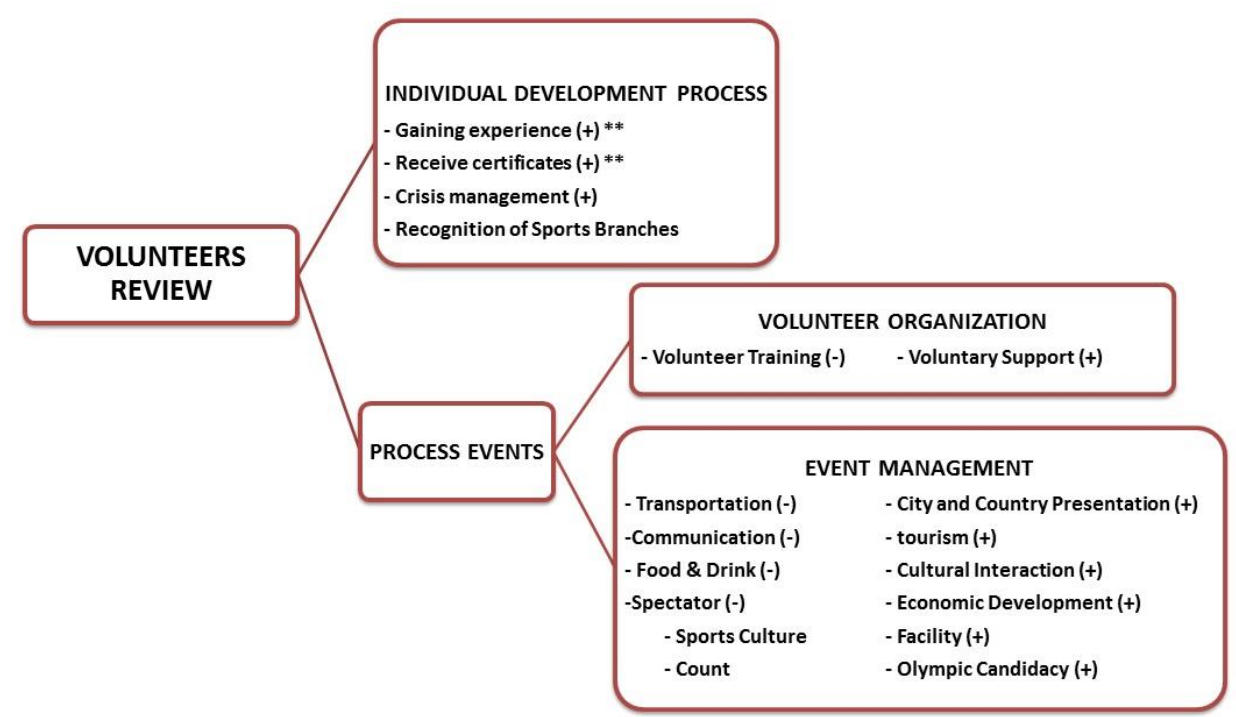

${ }^{*}(+)$ Positive Development, (-) negative Development, (**) Pre- Event Volunteer Expectations

Figure 6. Validation codes of volunteers.

Tütüncü et al. (2013); in study named 'assessment of the motivation of the volunteers participated in Recreation therapy camp', Özşen (2012); thesis named 'Determining whether the expectations of volunteers has met' and Koşan \& Güneş (2009); in study named '2011 Winter Universiade'; reached to similar conclusions such as gaining new experiences, providing individual gains, to socialize and meet with people from different cultures.

Volunteers employing in all national and international organizations take charge are contrary to volunteerism principle. But, some informations obtained such as the participants of this organization had salaried volunteers. Sertbaş (2006); makes the definition of the VOLUNTEERISM as individuals spend their free time in activities that others thought it would be useful for others without any material provision waiting in activities. Özşen (2012); the volunteer is the one who works willingly and get responsability to be usefel for others in his free time. Tütüncü et al (2013); Volunteerism is a social non-profit organization. As considered an opportunity to help others, these activities are carried out in order to benefit the community.

The assessment of organizational processes; this process involves the administration of volunteer organization and activity.

Volunteer Organization assessment; the data emphasizing the lack of voluntary education and the importance of voluntary about volunteer support had been observed.
The lack of voluntary education; participants stated that full education was not given as predicted, and that the education given was not enough. Based on these findings, participants thoughts;

"I think that no sufficient and a good education according to the department is given" "bus companies are rented from the city and drivers have been brought and that drivers do not know exactly this place" "the education is zero, we are not educated, for exampe they had promissed an education of 2 weeks but it was only 2 hours. So, education in human capital is a need" ( P2, P5, P10, P12, P15, P17, K19).

“...Disruptions were occured about education...We colsuted and get education but $i$ have not any information about the plants, $i$ learned when $i$ arrived in the morning. This was like this for each plant. We have learned the inside of plants when we arrived." "They had promissed an education of 2 weeks but it was only 2 hours. So, education in human capital is a need." (P2, P5, P11, P15, P19)

"Certainly there, for example, if we talk about the departments, it is required to prepare a booklet on what volunteers of each will do and to educate volunteers because volunteers do not know what they will do when they start to work, so they are lack of assisting subject, do not know their limits how much we can help, if $i$ do this, is it in my responsability or not, they have to know their rights because they can be encoutered by others if it is not out of their responsability area. I think that we are incomplete in that issue. We have to face it out and 
develop it. Volunteers need more education and more awareness." (P2, P5, P11..)

"It could be more planed and disciplined. There was no line defining pecking order. Nobody was informed us about towards who we are responsable and till where we can intervene and we became the victims. Supervisors made distinctions between people. They were acting differently to people." (P9, P28, P29...)

"Here we are constantly active and frankly overrated. Our minister was very interested with us and also precised how he attached importance to us." (P12, $P 22, P 26 \ldots$.

"However; a well-prepared volunteers' team makes it easier to achieve success in the organization. To create volunteers with high motivation and satifaction, norms of behavior must to be identified and be taken into account" (5)

When we look at the opinion on the assessment of the effectiveness of the voluntary process; we reach the data about examinated in two parts the the gainings and lacks of the activity. We have reached the data about that; XVII. Mediterranean Games, contribute to the promotion of the city and the country, develop tourism of country and city, provide cultural interaction with sportsmen from different countries and spectators, contribute to economic development of the city through local and foreign participants from many countries of the world, make the city gain resort in many international criteria, and the activities in this organization made contributions to the Olympic candidacy. Furthermore they indicated that they had experienced serious problems in terms of transportation, communication, eating and drinkingthe number of spectators. Participants precised that they had a lot of disruptions and affects in transportation during the Games as well as the disruption of transportation themselves and of sportsmen, referees, etc. Based on these findings, participants thoughts;

"People who do not know Mersini are woking in such a position that they have to know Mersin, they have to guide but do not know." "...bus companies are rented from the city and drivers have been brought and that drivers do not know exactly this place" "The drivers have been brought from Mersin but they do not know here and how to work. They had said they would show them, but unfortunately not yet" (P10, P12, P17).

"We had experienced troubles on issue of food, in early food packages were good but then the food came expiration date, we could not eat of course" (P14, P17, P29).

"Everyone thinks himself superior, there was no line defining pecking order. So this left us in a very difficult situation."

"...very few people are coming as a spectator, and most of spectators are relations of sportmen" "It was very weak in terms of spectators, many people was blocked to come to plant, if these dumps happens, if we do not create a consciousness in this way, how can we make Olympics" (P4, P6, P8, P11, P15, P17,P21, P25, P27).

"There was too much trouble about transportation. The service hour and competition hours were not matching. We are waiting 2-3 hours for transportation service. And of couse, we had experienced too much problem about departure and arrivals" (P1, P2, P7, P8, P11, P12, P14, P15, P17, P18, P21, P29).

\section{CONCLUSION}

As during all great organization; it is detected that volunteers are paid in the mediterranean games. it is contrary to volunteerism principle. according to state of the world's volunteerism report (2011); it is indicated as 'spend their free time in activities that others thought it would be useful for others without any material provision waiting in activities' Also, Police Academy student came to this activity as weekly obligatory stage, and this was not match with voolunteerism principles. However; All of the volunteers who participated in this research indicated that they provide personal benefit from this event. All emphasized that they would be willing again although they are volunteer for the first time a sporting event.

The volunteer group consisting of young people and students, and those who will benefit in the country in the international sports organizations (tourism, city and country representation) declared positive opinion. The most important deficiencies were in the organization; transportation, communication, eating and drinking and the number and nature of spectators. Number of spectators is almost none in many branches. Especially spectators were brought for the competition of national sportsmen. Their declaration is very important about that they are supported seriously and significantly. However, they found still insufficient voluntary education.

Education is the most important continuing problem of our country. Volunteers clearly stated that the sport culture is not in both their mentality 
and spectators. It attracts attention that especially volunteers have not known come of sport branchs.

Education programs will be given to volunteers who want to take part in sport organizations, course contents and education programs on practice ares and institutionalization will reinforce the idea of sportif volunteering. Sports organization will be effective as the executive center of the application. Especially with the network which will be established with educational institutions, basic volunteer education programs will be able to activated (8).

In result of these evaluations; Volunteers who want to take part in large and / or multi sport organizations, must be educated regularly and systematically. It is recommended importantly to constitue and applies programs attending to spread the sport culture in aim of evaluation of free time in all education system. Also, it is recommended importantly to create the common data in which contact infos of volunteers employed at once such an organization and to share this data with the relevant units.

\section{REFERENCES}

1. Auld C. Behavioural characteristics of student volunteers, Australian Journal On Volunteerıng, 2004; 9(2): 8-18.

2. Daly JA. Volunteers in South Australian Sport: A study. Canberra: Australian Sport Commission, 1991.

3. Status Report of Volunteerism in the World. Publication: United Nation Volunteers (UNV), 2011.

4. Fernandez A, Reguena G. Volunteering Versus Olimpizm. Volunteers Global Society and the Olympic Movement.
Papers of Symposium Held In Lausuenne, 24 - 26 Nowember, 1999: 2-5.

5. Koşan A, Güneş E. Volunteerism and Erzurum 2011 Winter Universiades. Journal of Atatürk University Social Sciences, 2009; 13(2): 1-18.

6. Mersin Youth Services and Sport Provincial Directorate. http://mersin.gsb.gov.tr/Sayfalar/Akdeniz-Oyunlar\%C4\%B1Tarih\%C3\%A7 esi.aspx (access: 22.09.2013, s. 15.55)

7. Özşen G. Determining Weather Expectations of Voluntary Participants who served in 2010 World Basketball Championship are met or not, Marmara University Institute of Health Sciences, Master Thesis, İstanbul, 2012.

8. Sertbaş K. UNIVERSIADE2005 Reasons of Voluntary Human Resources who were on duty in İzmir Games for Attending to the Organization and Analysis of Motivational Factors, Dissertation which is proposed by Kocaeli University Institute of Health Sciences' Regulations for Department of Physical Education and Sport Programme, Kocaeli, 2006.

9. Sertbaş K, Atalı L, Taşkııran Y, Gönener A. 'Voluntary Human Resources Organization', Practice Sample for Turkey in Sport, VII. International Sports Sciences Congress, Antalya, 2002.

10. Strigas AD. Motivational factors for student volunteers and the development of an incentive typology in sport settings. Research Quarterly for Exercise and Sport, 2003; 74, 90.

11. Tütüncü Ö, Aydın İ, Koca M, Kosova S, Avcı N. Evaluation of Motivations of the Volunteers participating in Recreational Therapy Camp, II. Recreation Research Congress, Aydin, 2013.

12. National Youth and Sport Policy Certificate. http://www.gsb.gov.tr/content/files/ulusalgenclikvesporpoliti kasi.pdf (access: 16.09. 2013, p. 38).

13. Wikipedia. http://tr.wikipedia.org/wiki/Akdeniz_Oyunlar \%C4\%B1, 2013, (Erişim:25.09.2013, pp. 22.35)

14. Yıldırım A, Şimşek H. Research Methods in Social Sciences, Ankara: Seçkin Publishing, 2006. 